This is a post-peer-review, pre-copyedit version of an article published in the Journal of Abnormal Child Psychology. The final authenticated version is available online at: http://dx.doi.org/ 10.1007/s10802-016-0232-y

Controlled social interaction tasks to measure self-perceptions:

No evidence of positive illusions in boys with ADHD

\author{
Yuanyuan Jiang ${ }^{\mathrm{a}}$ \\ Charlotte Johnston ${ }^{\mathrm{b}}$ \\ University of British Columbia
}

${ }^{a}$ Corresponding Author: Department of Psychiatry, University of California, San Francisco, 401 Parnassus Ave., San Francisco, C.A., United States, 94143, yuan.jiang@ucsf.edu, phone: 1-415-476-6931, fax: 1-415-502-6361.

${ }^{\mathrm{b}}$ Department of Psychology, University of British Columbia, 2136 West Mall, Vancouver, B.C., Canada, V6T 1Z4, cjohnston@psych.ubc.ca. 


\begin{abstract}
Studies have suggested that children with Attention-Deficit/Hyperactivity Disorder (ADHD) possess a Positive Illusory Bias (PIB) where they have higher self-perceptions of competence than more objective measures of their competence. However, recent research calls into question the primary methodology of these studies, that is, difference scores. This study investigated the PIB in boys with ADHD within the social domain using a novel methodology that refrains from using difference scores. Eighty-one 8- to 12-year-old boys with and without ADHD completed social interaction tasks where their actual social performance was made comparable, allowing for tests of between-group differences in self-perceptions that do not rely on difference scores. In addition, to examine whether clarity of social feedback moderates the presence of the PIB, the social tasks presented unclear, clear positive, or clear negative feedback. Boys rated how well they performed in each social interaction task, and these ratings were compared between ADHD and non-ADHD groups. Compared to the non-ADHD group, boys with ADHD did not show a PIB in their ratings of performance on the social tasks. There also was no moderation of boys' ratings by type of feedback received. In contrast, when the PIB was calculated using difference scores based on child and parent ratings of child competence, boys with ADHD showed a PIB compared to boys without ADHD. These findings call attention to the need to re-examine the phenomenon of the PIB using methodologies outside of difference scores.
\end{abstract}

Keywords: ADHD, Positive Illusory Bias, PIB, overestimations, self-perceptions 
Controlled social interaction tasks to measure self-perceptions:

No evidence of positive illusions in boys with ADHD

Children with Attention-Deficit/Hyperactivity Disorder (ADHD) demonstrate developmentally inappropriate levels of inattention, and/or hyperactivity/or impulsivity (American Psychiatric Association, 2013). In addition, past studies suggest that these children have a Positive Illusory Bias (PIB), such that they view their abilities more positively than their actual competence (Owens, Goldfine, Evangelista, Hoza, \& Kaiser, 2007). This PIB is argued to be different from the positive self-views of typically-developing children because it is (1) greater in degree and persists despite the frequent failures of children with ADHD, and (2) counterintuitive and maladaptive (Owens et al., 2007) as it is unrelated to persistence and motivation (Hoza, Pelham, Waschbusch, Kipp, \& Owens, 2001; Milich \& Okazaki, 1991) but is instead related to maladjustment. For instance, the PIB, typically measured with discrepancy scores, has been associated with risky driving behavior (Hoza et al., 2013), behavioral challenges and social deficits (Kaiser, Hoza, Pelham, Gnagy, \& Greiner, 2008; Linnea, Hoza, Tomb, \& Kaiser, 2012; Ohan \& Johnston, 2011), and lower response to treatment (Mikami, Calhoun, \& Abikoff, 2010). However, it is possible that these findings may need to be interpreted with caution given the limitations associated with the use of discrepancy or difference scores (Laird \& Weems, 2011).

Various explanations for the PIB have been proposed, including the neuropsychological deficit hypothesis and the self-protective hypothesis (see Owens et al., 2007 for a review). The neuropsychological deficit hypothesis proposes that children with ADHD have executive functioning deficits that render them incapable of perceiving their competence realistically, whereas the self-protective hypothesis indicates that children with ADHD have inflated levels of 
self-competence because they are defensively protecting their self-esteem against their many experiences of failure (Diener \& Milich, 1997; Owens et al., 2007). Despite some research attention, the support for these proposed mechanisms remains mixed and they may not be mutually exclusive or exhaustive (e.g., Hoza et al., 2004; Hoza, Pelham, Dobbs, Pillow, \& Owens, 2002; Hoza, Vaughn, Waschbusch, Murray-Close, \& McCabe, 2012; Hoza, Waschbusch, Pelham, Molina, \& Milich, 2000; McQuade et al., 2011; Ohan \& Johnston, 2002). Before further study of the mechanisms, we argue that careful attention should be paid to measurement issues in the assessment of the PIB. Many studies have investigated the PIB in children with ADHD (Owens et al., 2007). Despite this evidence, however, there are reasons to question the methods used to assess the PIB and the conditions under which it occurs. This study focuses on addressing whether an alternative method of assessment can confirm the PIB in children with ADHD as well as whether social feedback is a moderator of the PIB.

\section{Measuring the PIB}

The PIB has been conceptualized by past studies as a difference between children's selfreports of competence and more objective measures of competence (Hoza et al., 2002). Although the more objective measures are at times based on children's actual performance on achievement or social tasks (e.g., Diener \& Milich, 1997; Ohan \& Johnston, 2011; Owens \& Hoza, 2003), more typical methodology uses the ratings of others who know the child well (i.e., parents or teachers) to index actual competence. The majority of studies have used Harter's Self-Perception Profile for Children (SPPC; Harter, 1985) to measure child self-reports and parent or teacher reports of competence. Most commonly, the PIB involves creating difference scores by subtracting informant reports from child reports (Owens et al., 2007), and standardizing the two components of the difference score is recommended (De Los Reyes \& Kazdin, 2004). 


\section{The PIB Assessed Using Difference Scores}

The vast majority of studies that have used the difference score approach have supported the presence of a PIB in children with ADHD irrespective of whether the more objective measures used were mother-ratings, father-ratings, teacher-ratings, or lab-based tasks (e.g., Diener \& Milich, 1997; Emeh \& Mikami, 2012; Evangelista, Owens, Golden, \& Pelham, 2008; Hoza et al., 2004; Hoza et al., 2002; Hoza et al., 2001; Hoza et al., 2012; Ohan \& Johnston, 2011; Owens \& Hoza, 2003). Unfortunately, the use of difference scores to capture the PIB has serious limitations that compromise the conclusions that can be drawn from this literature. A major weakness (Edwards, 1994; Griffin, Murray, \& Gonzalez, 1999) is that significant associations between a difference score (i.e., the PIB) and a third variable (i.e., ADHD status) may be entirely accounted for by the association between only one component of the difference score (i.e., the informant rater component of the PIB) and the third variable (i.e., ADHD status). In particular, Laird and Weems (2011) convincingly demonstrated that a relation between a difference score and a third variable will arise anytime the components of the difference score are unequally related to the third variable. Therefore, as the PIB difference score is composed of both child self-reports and parent reports, if parent reports are more strongly related to child ADHD status than are child self-reports, then a significant association between the PIB and ADHD status will be present, despite the fact that it is accounted for only or primarily by the relation between parent reports and ADHD status. Given the well-established impairments that children with ADHD have in various life domains, it is quite possible that their lower competence as indexed by informant reports may drive the PIB difference score. Therefore, it is unclear how best to interpret the results of studies of the PIB using difference scores. 


\section{Attempts to Address Difference Score Limitations}

An early approach that circumvented the use of difference scores examined the PIB based solely on child self-reports of competence. These studies used group-level comparisons and did not assess the PIB at the level of the individual child. They yielded various conclusions, ranging from evidence that boys with ADHD have lower self-perceptions than boys without (e.g., Ialongo, Lopez, Horn, Pascoe, \& Greenberg, 1994; Treuting \& Hinshaw, 2001), to nonsignificant differences in self-perceptions (e.g., Hoza, Pelham, Milich, Pillow, \& McBride, 1993; Hoza et al., 2001; Owens \& Hoza, 2003; Treuting \& Hinshaw, 2001), to evidence of higher selfperceptions (e.g., Hoza et al., 2001; Milich \& Okazaki, 1991; O’Neill \& Douglas, 1991).

Some studies have attempted to address the limitations of difference scores by controlling for the contributions of impairment. For instance, Mikami et al. (2010) found that the PIB was uniquely predictive of response to treatment among children with ADHD, even when controlling for the child's level of impairment. Similarly, Ohan and Johnston (2011) found that after controlling for impairment, the PIB in the social domain was still negatively related to functioning, and Jia, Jiang, and Mikami (2015) reported that both the PIB and measures of competence were unique predictors of maladjustment. However, in contrast, Swanson, Owens, and Hinshaw (2012) found that objective measures of impairment were more strongly associated with later adjustment in children with ADHD than was the PIB. In other studies, greater PIB among children with ADHD has been linked to higher impairment (e.g., Hoza et al., 2002; Hoza et al., 2004; McQuade et al., 2011), in line with the possibility that the PIB is driven by impairment, although this finding is not entirely consistent (e.g., Evangelista et al., 2008).

In addition to measuring the impact of impairment on the PIB, polynomial regressions have been proposed as an alternative to difference scores, where the individual PIB difference 
score components, their interaction, and the quadratic terms of the components are used to predict ADHD status (Laird \& De Los Reyes, 2013; Laird \& Weems, 2011). To our knowledge, only one study has examined the PIB using polynomial regressions. Interestingly, this study used response surface graphing, and found results suggesting that when teacher-reported competence was low, ADHD symptoms were related to both high and low self-perceptions among young adolescents (Fefer, Ogg, \& Dedrick, 2015).

Another study used tasks with individualized levels of difficulty to measure the PIB. Helseth, Bruce, and Waschbusch (2013) had boys with and without ADHD complete four tasks of physical ability. A baseline level of performance for each boy was identified for each task, and three trials of each task were designed with difficulty levels at baseline, and $8 \%$ and $13 \%$ above baseline. Results indicated that boys with ADHD overestimated their ability to perform these tasks compared to boys without ADHD, supportive of a PIB. Although Helseth et al.'s design may allow for more comparable levels of actual performance between groups, the sample size of the study was relatively small and performance was studied only within the physical domain. It is important to build on this study by assessing other important life domains.

Overall, across studies, findings regarding the existence of the PIB in children with ADHD vary, and the use of difference scores limit conclusions. The current study extends previous research by examining the PIB in the social domain using difference scores constructed from rating scales as well as lab tasks where the actual performance of boys with and without ADHD is made comparable, and children's estimates of competence can be directly compared to test whether children with ADHD overestimate their competence. 


\section{Feedback Clarity as a Possible PIB Moderator}

In addition to measurement difficulties, another possible explanation for the inconclusive results of existing studies lies in potential moderators of the PIB in children with ADHD. One possible candidate as a moderator is the clarity of feedback that children receive about their performance, which could be consistent with the two leading explanatory mechanisms proposed for the PIB (e.g., Owens et al., 2007). Corresponding with the neuropsychological deficit hypothesis, children with ADHD may exhibit particularly poor self-awareness when confronted with feedback that is ambiguous and difficult to interpret, with more accurate self-estimates in the presence of clear feedback. Similarly, in line with the self-protective hypothesis, conditions of ambiguous feedback may allow the greatest room for positive interpretative bias in the estimates made by children with ADHD to protect their self-esteem. Thus, both of these mechanisms may be consistent with the possibility that the presence of the PIB may be conditional on clarity of feedback and may be greatest under conditions of ambiguous feedback.

Previous studies have not directly tested the influence of clarity of feedback on the PIB. However, some studies showing a PIB have used procedures that provide no feedback to the child regarding performance or have not specified that any feedback was provided (e.g., Diener \& Milich, 1997). In contrast, in Hoza et al.’s (2000) study, self-evaluations completed immediately following clear positive and negative feedback about a social interaction did not yield a PIB in boys with ADHD. These different results hint at the possibility that boys with ADHD may be more likely show a PIB when they receive no or unclear feedback regarding their performance, compared to when they receive clear feedback. In this study, we directly test of the role of social feedback clarity as a moderator of the occurrence of the PIB. 


\section{Current Study}

This study was designed to clarify if, and under what conditions, boys with ADHD may

show a PIB. To enhance comparability with past studies of the PIB that have most often relied on exclusively male samples, this study's participants were also all boys. To address the methodological limitations of prior PIB methods (i.e., use of difference scores), we assessed boys' perceptions of their performance on social interaction tasks where the actual performance of boys with and without ADHD was made comparable. In these tasks, boys with and without ADHD interacted with computerized peers in a controlled manner such that their interactions were comparable in social appropriateness and effectiveness. These constraints allowed for an internally valid test of whether compared to boys without ADHD, boys with ADHD would overestimate their performance (i.e., show a PIB) when the actual level of performance (i.e., impairment or competence) was held constant between the ADHD and non-ADHD groups.

In addition, standardized difference scores composed of parent-reports subtracted from child-reports of competence were created to capture the PIB as measured by previous research, so as to be able to compare the results of this new methodology and the prior difference score approach. As previously mentioned, past PIB research has used rating scales and lab tasks. However, there is a paucity of studies that have used these two approaches in the same sample. It is very important to investigate the PIB across assessment methods.

To assess the potential of clarity of feedback in moderating the appearance of a PIB on this task, three levels of feedback from the computerized peer in the social interactions were used. Feedback regarding the child's performance was unclear (i.e., the computerized peer provided responses that were ambiguous in terms of how well the participating boy was performing), clearly positive (i.e., the computerized peer provided responses indicating that the 
boy was doing well socially), or clearly negative (i.e., the computerized peer's responses indicated that the boy was not doing well socially). Boys with ADHD were predicted to show a PIB using the previous difference score technique, but to not always show a PIB using the social interaction tasks that standardized actual performance. More specifically, on the social interaction tasks boys with ADHD were predicted to show a PIB only when they encountered unclear feedback, not when they encountered clear feedback (whether positive or negative).

\section{Methods}

\section{Participants}

Research Ethics Board approval was obtained for this study. Boys were recruited using community notices, a registry of families interested in research, ADHD support groups, and health professionals. To be eligible, boys needed to be between 8 and 12 years of age and to have spoken English for more than 3 years, and participating parents or caregivers had to have lived with their sons for more than 1 year. In addition, boys with significant developmental delays (assessed via parent report) were excluded.

The ADHD-IV Rating Scale (ADHD-IV RS; DuPaul, Power, Anastopoulos, \& Reid, 1998) was used by parents and teachers to rate the frequency of ADHD symptoms of participating boys in the past 6 months, using a 4-point Likert scale $(0=$ never or rarely, $1=$ sometimes, 2 = often, 3 = very often). The 18 items of this questionnaire correspond to the DSM criteria for ADHD (American Psychiatric Association, 2013). An item added to the questionnaire assessed the level of impairment in home or school functioning that ADHD symptoms caused. An age of onset question also was added to the parent version of the questionnaire. This questionnaire has demonstrated reliability and validity (DuPaul et al., 1998). In this study, the internal consistencies were .94 for the inattention items and .90 for the hyperactive/impulsive 
items for parent reports ( 78 mothers and 3 fathers). For teacher reports, the internal consistencies were .92 for the inattention items and .89 for the hyperactive/impulsive items.

Boys were categorized into the ADHD group if they: (1) met criteria for ADHD from parent or teacher ratings on the ADHD-IV RS (i.e., six or more symptoms of inattention and/or hyperactivity/impulsivity rated as occurring often or very often), (2) had a parent-reported age of onset of ADHD symptoms before 7 years, and (3) received parent and teacher ratings of 1 (sometimes), 2 (often), or 3 (very often) for level of impairment. ${ }^{1}$ Boys were included in the nonADHD group if they: (1) were reported by parents to have never had ADHD, learning problems, or any other psychological disorder, (2) had three or less parent-reported symptoms of inattention and three or less symptoms of hyperactivity/impulsivity, (3) had parent-reported ratings of less than 2 (often) for the level of impairment from symptoms at home or at school. Teacher ratings were not collected for the non-ADHD group.

Forty-two boys in the ADHD group and 55 boys in the non-ADHD group participated, along with their parent. Nine additional boys did not meet inclusion criteria for the ADHD group due to missing teacher symptom ratings, ratings of too few symptoms, or ratings of no impairment. Boys with co-occurring parent-reported learning disabilities were excluded from the non-ADHD group, but were not excluded from the ADHD group. One boy was excluded from the non-ADHD group due to parent-reported learning difficulties.

The boys that were included in data analysis not only met diagnostic criteria, but also demonstrated that they believed that the computerized peers in the social interaction tasks used in the study were real. Based on their responses to believability questions, 35 (83\%) of the 42 boys in the ADHD group, and $46(84 \%)$ of the 55 boys in the non-ADHD group believed that the

\footnotetext{
${ }^{1}$ Three boys included in the study were missing teacher ratings of impairment, but met all other research criteria for ADHD. Results did not differ depending on whether these three boys were included in analyses.
} 
computerized peers were real. There were no significant differences between believers and nonbelievers in ADHD status, socioeconomic status (SES), or measures of competence. However, non-believers were significantly older than believers, $F(1,102)=6.22, p<.05$, which makes sense in light of the increased cognitive sophistication of children who are older. Altogether, 35 boys with ADHD and 46 boys without ADHD were included in the final data analyses.

In the ADHD group, 29 (83\%) of the 35 boys were reported by parents to have been formally diagnosed with ADHD, and 18 (51\%) were currently on ADHD medication (14 were taking stimulants). Thirteen of the 14 boys on stimulants had not taken their medication for 24 hours prior to the study visit, and the remaining one boy had taken medication 10.5 hours before the study. Based on parent report, seven (20\%) boys from the ADHD group had co-occurring learning problems alone, four (11\%) had behavior problems, one $(3 \%)$ had learning problems along with motor coordination difficulties and anxiety, one (3\%) had learning and anxiety problems, another (3\%) had a speech delay, and another boy (3\%) had problems with anxiety. Families of boys with ADHD were on average lower middle-class, and non-ADHD group families were predominantly middle-class (see Table 1), based on Hollingshead's (1975) FourFactor Index of Social Status. There was a significant between-group difference in family SES. Twenty-three (66\%) families in the ADHD group had parents with married or common law status, whereas $43(93 \%)$ families in the non-ADHD group had married or common law status. Eleven (31\%) families in the ADHD group had divorced, separated, or single-parent status whereas three (7\%) families in the non-ADHD group had such status. The ADHD group had fewer married or common law families than the non-ADHD group, $p<.01$, Fisher's Exact Test.

With respect to ethnicity, 25 (71\%) boys in the ADHD group were classed as European/Canadian whereas $24(52 \%)$ boys in the non-ADHD group were of this ethnicity. Four 
(11\%) boys in the ADHD group and 18 (39\%) boys in the non-ADHD group were of East Asian ethnicity. Two (6\%) boys in the ADHD group and one $(2 \%)$ boy in the non-ADHD group were of South Asian ethnicity. One (3\%) boy in the ADHD group and one (2\%) boy in the non-ADHD group were of Hispanic ethnicity. One (2\%) boy in the non-ADHD group was of First Nations ethnicity. Three ( $9 \%$ ) boys in the ADHD group and one $(2 \%)$ boy in the non-ADHD group were of mixed ethnicity. Compared to the non-ADHD group, the ADHD group had more boys who were European/Canadian, $\chi^{2}(1)=3.78, p=.05$.

\section{Measures}

Social interaction tasks. In order to make comparable the social performances of boys with and without ADHD, three 5-minute computerized social interaction tasks were created, and to test the moderating role of social feedback, three types of social feedback were used across these tasks. In these tasks, each boy communicated via computer with three peers whom he was told were real. In reality, these peers were computerized and pre-programmed. ${ }^{2}$ Boys were instructed to interact with each peer on the computer, with the goal of getting the peer to like them. During the interactions, participating boys chose from two options for questions to ask the computerized peers and from another two options for responses to the computerized peers' questions. These options for both questions and responses differed in content but not in their level of social skill/appropriateness (e.g., "Hi, how are you?” versus "Hello, how are you?”,

\footnotetext{
${ }^{2}$ Pilot testing of the believability, valence, clarity, and social skill of the interactions was conducted by evaluating the response options and texts from the computerized peers using four 7-point Likert scales with anchors of 1 (not at all believable) to 7 (extremely believable) for believability, 1 (extremely negative to participant) to 7 (extremely positive to participant) for valence, 1 (not at all clear in conveying like/dislike) to 7 (extremely clear in conveying like/dislike) for clarity of feedback, and 1 (not at all equal in social skill/appropriateness) to 7 (extremely equal in social skill/appropriateness) for social skill. Pilot testing was conducted with undergraduate and graduate students with experience working with children. Texts were high on believability (average rating was 6.32), differed appropriately in valence (average ratings for the Negative, Unclear, and Positive conditions were 1.34, 3.89, and 7.00 , respectively) and clarity of feedback (average ratings for the Positive and Negative conditions were at or above 6.56 , and average rating for the Unclear condition was 2.82 ), and did not vary meaningfully in social skill (average rating was 6.78).
} 
"What's your favorite class?" versus "Do you have a class you like?", "Yes" versus "No"). In this way, the actual social performance of boys with and without ADHD was controlled.

In the clear positive feedback task, the computerized peer replied to boys with clearly positive judgments (e.g., "You are so cool", "You are pretty cool", "You're so right") and an agreeing statement (e.g., "I do too”, “I don’t either”, "Dogs are fun!'”) in response to each statement option chosen by the participant. In contrast, the computerized peer in the clear negative task provided clearly negative judgments (e.g., "You are not cool", "You are so strange", "You're so wrong”) and conflicting statements (e.g., “They're so boring”, "They're not fun!", "I really don't"). Finally, in the unclear feedback task, the computerized peer gave ambiguous answers (e.g., "You like swimming. I swim sometimes", "You don’t like school. I don't sometimes", "You like baseball more. It is ok").

For each interaction, boys had to select approximately 10 questions/responses, and computerized peers gave an average of five feedback statements. Computerized peers asked an average of five questions. As well, the questions/responses of the participating boys, and the questions and feedback statements of the computerized peers were embedded in approximately seven additional neutral statements of the computerized peers. Feedback task order was counterbalanced across boys.

Post-task self-evaluations of performance (PSP). After interactions with each of the computerized peers, boys rated their social performance in the interaction using a Post-task Selfevaluations of Performance (PSP) questionnaire developed for this study based on measures used in previous studies (e.g., Diener \& Milich, 1997; Hoza et al., 2000; Ohan \& Johnston, 2002). This questionnaire has four items: (1) "how well did you do in getting the boy to like you?", (2) "how much do you think the boy liked you?", (3) "how much do you think the boy liked talking 
to you?", and (4) "how much do you think the boy wanted to be friends with you?", each rated on a 9-point Likert scale. Scores were averaged across items. For the ADHD group, the internal consistencies for self-ratings were .85 for the unclear feedback task, .79 for the positive feedback task, and .86 for the negative feedback task. For the non-ADHD group, the internal consistencies were $.87, .85$, and 90 for the unclear, positive, and negative feedback tasks, respectively.

Self-perception profile for children (SPPC; Harter, 1985). Boys and their parents completed the SPPC to allow for replication of the findings of prior PIB studies that have employed difference scores to index the PIB. The social subscale of the SPPC has 6 items that ask how much children agree with statements of their social competence (e.g., "some kids would like to have a lot more friends but other kids have as many friends as they want"). Children first pick one of two sentences that they think is more like them, and then decide whether it is sort of true or really true. Parents completed the parent version of the SPPC, which was named the Parent's Rating Scale of Child's Actual Behavior (PRSCAB). Internal consistencies were .74 for child ratings, and .87 for parent ratings. Standardized difference scores were created by standardizing parent and child ratings, and subtracting parent ratings from child ratings.

\section{Procedure}

When parents contacted the lab, the study was explained, including the deception involved in having their child believe he is interacting with real peers during the study visit. Parents were asked not to inform their child that the peers they were to interact with were not real. At the beginning of the study, procedures were reviewed with parents and consent was obtained. Parents completed questionnaires while their children participated. Before starting the study, whether or not the boy had been told of the deception in the study was assessed with a series of questions (i.e., "what do you think we'll be doing today?", “do you know that you'll be 
talking to three boys?", "who do you think you're going to talk to?"). None of the boys reported knowing that they were going to talk with computerized peers. A research assistant then explained the study procedure to the boy, and told the boy that his goal for each social interaction task was to get the peer to like him. The boy was told that he could click buttons on the laptop computer to both respond to questions and ask questions of the peer. Child assent was gathered.

After interacting with each of the computerized peers, boys completed the PSP with a different research assistant. After all computer interactions were complete, boys filled out other questionnaires in counterbalanced order. At the conclusion of the study, boys were again assessed for whether they believed that the computerized peers were real with a series of questions (i.e., "what did you think about the three boys you talked to?", "do they seem like boys you see at school?", "was there anything strange about these boys?", "if so, how were they strange?", “were they all strange or were only one or two of them strange?”). Boys were then debriefed; it was explained that the peers they spoke with were computer programmed, and that deception was necessary for the purpose of the study. Afterwards, boys were involved in positive play activities with a research assistant. Families received a $\$ 15$ honorarium. The study length was approximately 60 minutes. $^{3}$

\section{Results}

\section{Descriptive Statistics}

Table 2 displays descriptive statistics for parent and child ratings of competence, and

Table 3 shows bivariate correlations among the dependent variables in the main analyses.

Demographic variables were not significantly related to PSP ratings or difference scores.

\footnotetext{
${ }^{3}$ Three (7\%) families in the non-ADHD group and four (11\%) families in the ADHD group participated in their homes. As well, 16 (35\%) families in the non-ADHD group and $18(51 \%)$ families in the ADHD group participated in this study while participating in a larger study at the lab. The remaining families in both groups participated at the lab, and only in the current study. Context of participation did not appear to influence the pattern of results.
} 


\section{Main Analyses}

ADHD status and feedback conditions. A repeated measures 2 (ADHD vs. no ADHD) x 3 (unclear vs. positive vs. negative feedback task) ANOVA was conducted with PSP ratings as the dependent variable. Partial eta-squared was used as a measure of effect size. Conventions for interpreting partial eta-squared (Cohen, 1988) are .01 (small), .06 (medium), and .14 (large). No significant interaction was found, $F(1.82,143.77)=1.40, p=.25$, partial $\eta^{2}=.02$, and no main effect of ADHD was present, $F(1,79)=.001, p=.97$, partial $\eta^{2}=.00 .{ }^{4}$ Only the main effect of feedback task was significant, $F(1.82,143.77)=451.77, p<.01$, partial $\eta^{2}=.85$. Pairwise comparisons showed that boys rated their performance more highly when they received positive feedback compared to unclear feedback, and rated their performance in the unclear feedback task more highly than when they received negative feedback, $p \mathrm{~s}<.01$. These findings (see Figure I) confirm that the feedback was effective in altering self-perceptions of performance. However, results also show no evidence of a PIB in boys with ADHD regardless of type of feedback.

ADHD status as related to difference scores. Comparing standardized difference scores between groups as a method of indexing the PIB indicated significantly higher standardized difference scores in the ADHD compared to non-ADHD group, $F(1,79)=4.95, p<.05, \eta^{2}=$ $.06^{5}$, confirming that in this sample, the difference score method yields evidence of a PIB in boys with ADHD.

\footnotetext{
${ }^{4}$ As previous studies have suggested that ADHD comorbidities are related to the PIB (e.g., Jiang \& Johnston, 2013), we also conducted these comparisons controlling for child aggressive (measured with the Child Behavior Checklist; Achenbach \& Rescorla, 2001) and depressive symptoms (measured with the Children's Depression Inventory 2; Kovacs, 2010). It was especially important to control for depressive symptoms in this analysis due to bivariate correlations showing that depressive symptoms were associated with social interaction self-evaluations. The pattern of significant results did not change with these covariates included.

${ }^{5}$ Controlling for aggressive symptoms reduced group differences in standardized difference scores, $F(1,78)=2.01$, $p=.16$, partial $\eta^{2}=.03$, but controlling for depressive symptoms did not change the significance of results.
} 


\section{Exploratory Analyses}

ADHD status and difference score components. Exploratory analyses were conducted to better understand the result that boys with ADHD did not show a PIB using social interaction tasks that equate performance, yet they did show a PIB assessed as the difference between child and parent reports of competence on the SPPC. The exploratory analyses examined how ADHD status was associated with each of the child and parent report components of the difference scores. A one-way ANOVA showed that ADHD and non-ADHD groups did not differ on childreported SPPC scores, $F(1,79)=.60, p=.44$, partial $\eta^{2}=.01$, but boys in the ADHD group had lower parent-reported PRSCAB ratings than those in the non-ADHD group, $F(1,79)=14.23, p$ $<.01$, partial $\eta^{2}=.15$. These findings support the suggestion that the difference score index of the PIB may be driven by the association of ADHD with parent-rated child impairment.

\section{Discussion}

Given the inconsistent results across studies regarding the PIB in children with ADHD, this study used a novel methodology that controlled actual performance, and tested whether the PIB is moderated by clarity of feedback. Boys with ADHD completed social interaction tasks in which their performance was held comparable to that of boys without ADHD. Each social interaction task had a different type of social feedback (clearly positive, clearly negative, and unclear). Boys were asked, after completing each interaction task, to rate how well they performed. To compare results across methodologies, boys and their parents also rated their selfperceptions of competence using a measure commonly used in the past, and standardized difference scores were created.

Although the feedback manipulation worked in that all boys' self-perception levels corresponded to the type of social feedback received, self-perceptions did not differ between 
boys with and without ADHD across any of the feedback tasks. However, results showed that boys with ADHD had a PIB when standardized difference scores of child and parent ratings of competence were compared between groups. Therefore, in a lab task where actual betweengroup performance was held constant, boys with ADHD did not exhibit a PIB. However, when using the prior way of operationalizing the PIB, this same group of boys with ADHD did show a PIB. Exploratory analyses showed no between-group differences on self-perceptions, but did show that the ADHD group had lower levels of parent-rated competence, further supporting that the relation between ADHD and the PIB may be accounted for by actual impairment.

\section{Main Findings}

No PIB in social interaction task where between-group performance is comparable.

Boys with ADHD showed no PIB on social interaction tasks that controlled their performance to be equivalent in social competence compared with boys without ADHD. However, these boys with ADHD did show a PIB compared to the non-ADHD group when difference scores are used. These findings provide support for the potential that the difference scores used by previous research to capture the PIB may be driven by the children's actual impairment levels rather than their self-perceptions. It is possible that children with ADHD may not have overestimations but instead, their PIB may reflect their greater impairment. Exploratory analyses further support this claim. Although it could be argued that children with ADHD are nevertheless mathematically overestimating their performance compared to a more objective estimate, this study demonstrates that boys with ADHD are not more likely to overestimate their performance and may view themselves as on par with boys without ADHD in a specific lab task.

Past studies have argued that the PIB in children with ADHD is clinically important because of its associations with measures of adjustment both in the present and future (e.g., Hoza 
et al., 2013; Kaiser et al., 2008; Linnea et al., 2012; Mikami et al., 2010; Ohan \& Johnston, 2011). However, the findings of this study suggest the need to further test the extent to which it is the lower impairment levels of children with ADHD, rather than the PIB, that are associated with such problems. Consistent with the results of Swanson et al. (2012), this study's findings question the incremental validity of the PIB construct above and beyond impairment. However, results are not consistent with those of Jia et al. (2015) and Ohan and Johnston (2011), which demonstrate that the PIB is related to functioning independent from impairment. It is possible that differences across studies in methodology or measures used to account for impairment may explain these divergent results. For instance, the actual impairment levels of those with ADHD may not have been adequately captured by the covariate measures used, and therefore, impairment may not have been fully controlled for despite the use of covariates.

As well, the PIB is a construct that is not unique to children with ADHD (Owens et al., 2007). For instance, child aggression and overestimations of competence are positively related (e.g., Brendgen, Vitaro, Turgeon, Poulin, \& Wanner, 2004; Hughes, Cavell, \& Grossman, 1997; Pardini, Barry, Barth, Lochman, \& Wells, 2006; Sandstrom \& Herlan, 2007). Studies also show that children with learning disorders overestimate their competence (e.g., Heath \& Glen, 2005). However, these populations of children are all significantly impaired, and our findings call attention to the need for a closer examination of the contributing role of impairment in the overestimations found in these groups of children as well.

Clarity of feedback does not moderate self-perceptions. No PIB was found in this study, so it is not surprising that clarity of feedback did not emerge as a moderator. This study suggests that regardless of the clarity or valence of social feedback (at least within this specific 
lab task), boys with ADHD can have accurate views of themselves (insofar as accuracy is defined as not different from boys without ADHD).

\section{Limitations and Future Directions}

This study has limitations along with strengths. Along with a new methodology, this study used well-established parent and child rating difference scores commonly used in this field (e.g., Owens et al., 2007) to assess the PIB. However, the PIB difference scores were based on ratings made with regard to global estimates of social competence, but the PIB as measured by the interaction tasks used ratings specific to social competence within the task context. The possibility exists that the results between the social interaction tasks and difference scores were inconsistent due to differences in the measurement of specific versus global competence constructs. Given that the social interaction task was specifically developed for this study, further tests of its validity also are needed. Although studies in the PIB literature have demonstrated the PIB using brief lab tasks (e.g., Milich \& Okazaki, 1992; Ohan \& Johnston, 2002, 2011; O’Neill \& Douglas, 1991), a lab task may not be adequate to capture the PIB in the same way as more global rating scales. Future studies of the PIB using multiple methodologies will provide very valuable insight. In addition, PIB difference scores were formed using parent-reports of competence, and future studies of this nature could benefit from using difference scores comprised of other, more objective indicators of competence.

Comprehensive diagnostic assessments involving clinical interviews were not used in this study to categorize boys into ADHD and non-ADHD groups. Thus, the ADHD status, severity, impairments, or comorbidities of these children cannot be as confidently stated as if more comprehensive diagnostic assessments had been used. In addition, the lack of teacher questionnaires for the non-ADHD group limits our assurance in the control nature of this sample. 
Future studies are needed to investigate the PIB in clinical samples defined using a more comprehensive diagnostic assessment of ADHD and co-occurring disorders.

The relevance of the social interaction tasks used here is underlined by the increasingly prevalent textual modes of communication. However, text communications differ substantially from in-person interactions. Therefore, it is difficult to determine the extent to which this study's results generalize to encounters in a richer social context. Future studies can use a similar methodology with in-person interactions. As well, the PIB has been shown to be present in domains outside of social competence, such as in the academic and behavioural domains (Owens et al., 2007). Different results may be found if the PIB were studied in these other domains, and it will be important for future research to do so.

All analyses only included boys assessed as believing in the reality of their interaction partners, which provided greater assurance that the social feedback had its intended effects. It is, of course, impossible to know for sure that children were not aware of the study deception. Prior studies using virtual social interactions show that computerized social rejection is meaningfully related to measures of social rejection, such as neural activation associated with pain, and selfreports of decreased happiness, lower inclusion, greater exclusion, more distress, higher sadness, and greater anger (e.g., Eisenberger, Lieberman, \& Williams, 2003; Masten et al., 2009; Silk et al., 2012). It will be useful for future studies to include measurements of emotional and physiological reactions of participants after the interaction tasks, so as to assess the believability and impact of the feedback tasks.

Although the fact that this study examined the PIB only in boys makes it similar to the samples of many past PIB studies, this restricted sample limits the generalizability of the study to girls. Interestingly, the two PIB studies that exclusively involved girls with ADHD have yielded 
mixed findings. Swanson et al.'s (2012) results suggest that the PIB may not be incrementally valid beyond impairment, whereas Ohan and Johnston (2011) demonstrate that girls with ADHD show a PIB. It will be necessary for future studies to directly investigate whether gender moderates these results. It also will be important to examine the PIB in larger samples, and in populations with different cultural backgrounds.

This study suggests that boys with ADHD may be accurate perceivers of their social performance if their performance is made comparable to boys without ADHD. This study used a research design that emphasized internal validity with a potential cost to external validity. In general, boys with ADHD are not as socially skilled as boys without ADHD, and therefore the forced equality of performance is not representative of the actual social performance of these children. However, this study's results support the idea that, at least under these controlled conditions, boys with ADHD do not overestimate their performance, and that the PIB as operationalized by difference scores may not be useful in terms of its incremental validity beyond impairment. Future studies are needed in order to expand this line of inquiry by, for instance, constraining the performance of both boys with and without ADHD to be in the impaired range, and examining whether boys with ADHD can continue to be accurate perceivers.

\section{Clinical Implications}

To our knowledge, this study is the first to test the PIB by comparing self-ratings of performance on a social interaction task with self-ratings on the SPPC rating scale in boys with and without ADHD. The interaction task controlled the actual performance of boys with and without ADHD, which allowed for evidence to support whether the relation between the PIB and ADHD is due to impairment. That boys with ADHD do not show a PIB when their performance is on par with typically-developing boys on this lab task provides further evidence suggesting 
that boys with ADHD may be able to perceive their performance accurately (insofar as accuracy is defined as being comparable to boys without ADHD), even with unclear social feedback.

This study's findings suggest that boys with ADHD may know how well they are doing in short, textual social interactions with their peers. Results raise questions regarding whether it is necessary to focus on increasing the accuracy of self-perceptions in ADHD interventions geared towards improving social functioning, and suggest instead that treatment to improve social behavior and acceptance may be more important. Such treatments as friendship interventions, parent training, classroom management, skills training, medication, or a combination of these interventions may be most helpful (e.g., American Academy of Pediatrics, 2011; De Boo \& Prins, 2007; Evans, Owens, \& Bunford, 2014; Mikami, 2010). Overall, findings suggest that it may be more beneficial to devote our resources to strengthening the actual competence of children with ADHD, rather than focusing on lowering their self-perceptions.

\section{Conclusion}

This study suggests that difference scores may show limitations as measures of the PIB in children with ADHD, and supports the idea that the relationship between ADHD and the PIB in the social domain may be more likely due to impairment levels associated with ADHD, and less likely due to inflated child self-reports of competence. When the social performance of ADHD and non-ADHD groups was made comparable on a social interaction task, boys with ADHD had self-perceptions on par with boys without ADHD. However, these same boys showed a PIB when self-perceptions were measured using difference scores constructed from parent and child rating scales. In sum, this study supports the idea that difference scores may have significant limitations in capturing the PIB in children with ADHD, and thus, it may be very important for future studies of the PIB to use methodologies beyond difference scores. 
Ethical approval: All procedures performed in studies involving human participants were in accordance with the ethical standards of the institutional and/or national research committee and with the 1964 Helsinki declaration and its later amendments or comparable ethical standards. Informed consent: Informed consent was obtained from all individual participants included in the study.

Acknowledgements: Many thanks to our participants as well as to our research assistants, Momoko Sato, Alejandra Botia, Bonnie Yuen, Emily Kuo, Cally Fung, Dexter McMillan, and Juin Lee. During this study, the first author was supported by a Vanier Canada Graduate Scholarship. As well, this study was funded by a grant from the Canadian Institutes of Health Research to the second author (CIHR 2010 MOP 106586).

Conflicts of interest disclosure: The authors declare that they have no conflicts of interest. 


\section{References}

Achenbach, T. M., \& Rescorla, L. A. (2001). Manual for the ASEBA school-age forms \& Profiles. Burlington, VT: University of Vermont.

American Academy of Pediatrics (2011). ADHD: Clinical practice guideline for the diagnosis, evaluation, and treatment of Attention-Deficit/Hyperactivity Disorder in children and adolescents. Pediatrics, 128, 1-16. doi:10.1542/peds.2011-2654

American Psychiatric Association (2013). Diagnostic and statistical manual of mental disorders (5th ed.). Washington, DC: American Psychiatric Association.

Brendgen, M., Vitaro, F., Turgeon, L., Poulin, F., \& Wanner, B. (2004). Is there a dark side of positive illusions? Overestimation of social competence and subsequent adjustment in aggressive and nonaggressive children. Journal of Abnormal Child Psychology, 32, 305320. doi:10.1023/B:JACP.0000026144.08470.cd

Cohen, J. (1988). Statistical power analysis for the behavioral sciences. Hillsdale, NJ: Lawrence Erlbaum Associates.

De Boo, G. M., \& Prins, P. J. M. (2007). Social incompetence in children with ADHD: Possible moderators and mediators in social-skills training. Clinical Psychology Review, 27, 78-97. doi:10.1016/j.cpr.2006.03.006

De Los Reyes, A., \& Kazdin, A. E. (2004). Measuring informant discrepancies in clinical child research. Psychological Assessment, 16, 330-334. doi:10.1037/1040-3590.16.3.330

Diener, M. B., \& Milich, R. (1997). Effects of positive feedback on the social interactions of boys with attention deficit hyperactivity disorder: A test of the self-protective hypothesis. Journal of Clinical Child Psychology, 26, 256-265. doi:10.1207/s15374424jccp2603_4 
DuPaul, G. J., Power, T. J., Anastopoulos, A. D., \& Reid, R. (1998). ADHD Rating Scale-IV: Checklists, norms, and clinical interpretation. New York, NY: Guilford Press.

Edwards, J. R. (1994). The study of congruence in organizational behavior research: Critique and a proposed alternative. Organizational Behavior and Human Decision Processes, 58, 51100. doi:10.1006/obhd.1994.1029

Eisenberger, N. I., Lieberman, M. D., \& Williams, K. D. (2003). Does rejection hurt? An fMRI study of social exclusion. Science, 302, 290-292. doi:10.1126/science.1089134

Emeh, C. C., \& Mikami, A. Y. (2012). The influence of parent behaviors on positive illusory bias in children with ADHD. Journal of Attention Disorders. Advance online publication. doi:10.1177/1087054712441831

Evangelista, N. M., Owens, J. S., Golden, C. M., \& Pelham, W. E. Jr. (2008). The positive illusory bias: Do inflated self-perceptions in children with ADHD generalize to perceptions of others? Journal of Abnormal Child Psychology, 36, 779-791. doi:10.1007/s10802-007-9210-8

Evans, S. W., Owens, J. S., \& Bunford, N. (2014) Evidence-based psychosocial treatments for children and adolescents with attention-deficit/hyperactivity disorder. Journal of Clinical Child and Adolescent Psychology, 43, 527-551. doi:10.1080/15374416.2013.850700

Fefer, S. A., Ogg, J. A., \& Dedrick, R. F. (2015). Use of polynomial regression to investigate biased self-perceptions and ADHD symptoms in young adolescents. Journal of Attention Disorders. First published on March 11, 2015 as doi:10.1177/1087054715573993

Griffin, D., Murray, S., \& Gonzalez, R. (1999). Difference score correlations in relationship research: A conceptual primer. Personal Relationships, 6, 505-518. doi:10.1111/j.14756811.1999.tb00206.x 
Harter, S. (1985). Manual for the Self-Perception Profile for Children. Denver: University of Denver Department of Developmental Psychology.

Heath, N. L., \& Glen, T. (2005). Positive illusory bias and the self-protective hypothesis in children with learning disabilities. Journal of Clinical Child and Adolescent Psychology, 34, 272-281. doi:10.1207/s15374424jccp3402_6

Helseth, S. A., Bruce, B. S., \& Waschbusch, D. A. (2013). Overestimation of physical abilities among boys with and without ADHD. Journal of Attention Disorders. First published on July 23, 2013 as doi:10.1177/1087054713496463

Hollingshead, A. B. (1975). Four-factor index of social status. New Haven, CT: Yale University Press.

Hoza, B., Gerdes, A. C., Hinshaw, S. P., Pelham, W. E. Jr., Abikoff, H. B., Greenhill, L. L., . . Wigal, T. (2004). Self-perceptions of competence in children with ADHD and comparison children. Journal of Consulting and Clinical Psychology, 72, 382-391. doi:10.1037/0022-006X.72.3.382

Hoza, B., McQuade, J. D., Murray-Close, D., Shoulberg, E., Molina, B. S. G., Arnold, L. E., ... Hechtman, L. (2013). Does childhood positive self-perceptual bias mediate adolescent risky behavior in youth from the MTA study? Journal of Consulting and Clinical Psychology, 81, 846-858. doi:10.1037/a0033536

Hoza, B., Pelham, W. E., Dobbs, J., Pillow, D. R., \& Owens, J.S. (2002). Do boys with Attention-Deficit/Hyperactivity Disorder have positive illusory self-concepts? Journal of Abnormal Psychology, 111, 268-278. doi:10.1037/0021-843X.111.2.268 
Hoza, B., Pelham, W. E., Milich, R., \& Pillow, D, \& McBride, K. (1993). The self-perceptions and attributions of Attention Deficit Hyperactivity Disordered and nonreferred boys. Journal of Abnormal Child Psychology, 21, 271-286. doi:10.1007/BF00917535

Hoza, B., Pelham, W. E, Waschbusch, D. A., Kipp, H., \& Owens, J. S. (2001). Academic task persistence of normally achieving ADHD and control boys: Performance, selfevaluations, and attributions. Journal of Consulting and Clinical Psychology, 69, 271283. doi:10.1037/0022-006X.69.2.271

Hoza, B., Vaughn, A., Waschbusch, D. A., Murray-Close, D., \& McCabe, G. (2012). Can children with ADHD be motivated to reduce bias in self-reports of competence? Journal of Consulting and Clinical Psychology, 80, 245-254. doi:10.1037/a0027299

Hoza, B., Waschbusch, D. A., Pelham, W. E., Molina, B. S. G., \& Milich, R. (2000). Attentiondeficit/hyperactivity disordered and control boys' responses to social success and failure. Child Development, 71, 432-446. doi:10.1111/1467-8624.00155

Hughes, J. N., Cavell, T. A., \& Grossman, P. B. (1997). A positive view of self: Risk or protection for aggressive children? Development and Psychopathology, 9, 75-94. doi:10.1017/S0954579497001077

Ialongo, N. S., Lopez, M., Horn, W. F., Pascoe, J. M., \& Greenberg, G. (1994). Effects of psychostimulant medication on self-perceptions of competence, control, and mood in children with attention deficit hyperactivity disorder. Journal of Clinical Child Psychology, 23, 161-173. doi:10.1207/s15374424jccp2302_6

Jia, M., Jiang, Y., \& Mikami, A. Y. (2015). Positively biased self-perceptions in children with ADHD: Unique predictor of future maladjustment. Journal of Abnormal Child Psychology, 44, 575-586. doi:10.1007/s10802-015-0056-1 
Jiang, Y., \& Johnston, C. (2013). Co-occurring aggressive and depressive symptoms as related to overestimations of competence in children with Attention-Deficit/Hyperactivity Disorder. Clinical Child and Family Psychology Review, 17, 157-172. doi:10.1007/s10567-0130158-7

Kaiser, N. M., Hoza, B., Pelham, W. E., Gnagy, E., \& Greiner, A. R. (2008). ADHD status and degree of positive illusions: Moderational and mediational relations with actual behavior. Journal of Attention Disorders, 12, 227-238. doi:10.1177/1087054707311661

Kovacs, M. (2010). CDI 2: Children's Depression Inventory Technical Manual (2 $2^{\text {nd }}$ ed.). North Tonawanda, NJ: Multi-Health Systems.

Laird, R. D., \& De Los Reyes, A. (2013). Testing informant discrepancies are predictors of early adolescent psychopathology: Why difference scores cannot tell you what you want to know and how polynomial regression may. Journal of Abnormal Child Psychology, 41, 114. doi:10.1007/s10802-012-9659-y

Laird, R. D., \& Weems, C. F. (2011). The equivalence of regression models using difference scores and models using separate scores for each informant: Implications for the study of informant discrepancies. Psychological Assessment, 23, 388-397. doi:10.1037/a0021926

Linnea, K., Hoza, B., Tomb, M., \& Kaiser, N. (2012). Does a positive bias relate to social behavior in children with ADHD? Behavior Therapy, 43, 862-875. doi:10.1016/j.beth.2012.05.004

Masten, C. L., Eisenberger, N. I., Borofsky, L. A., Pfeifer, J. H., McNealy, K., Mazziotta, J. C., \& Dapretto, M. (2009). Neural correlates of social exclusion during adolescence: Understanding the distress of peer rejection. Social Cognitive and Affective Neuroscience, 4, 143-157. doi:10.1093/scan/nsp007 
McQuade, J. D., Tomb, M., Hoza, B., Waschbusch, D. A., Hurt, E. A., \& Vaughn, A. J. (2011). Cognitive deficits and positively biased self-perceptions in children with ADHD. Journal of Abnormal Child Psychology, 39, 307-319. doi:10.1007/s10802-010-9453-7

Mikami, A. Y. (2010). The importance of friendship for youth with attentiondeficit/hyperactivity disorder. Clinical Child and Family Psychology Review, 13, 181-198. doi:10.1007/s10567-010-0067-y

Mikami, A. Y., Calhoun, C. D., \& Abikoff, H. B. (2010). Positive illusory bias and response to behavioral treatment among children with Attention-Deficit/Hyperactivity Disorder. Journal of Clinical Child and Adolescent Psychology, 39, 373-385. doi:10.1080/15374411003691735

Milich, R., \& Okazaki, M. (1991). An examination of learned helplessness among attentiondeficit disordered boys. Journal of Abnormal Child Psychology, 19, 607-623. doi:10.1007/BF00925823

Ohan, J. L., \& Johnston, C. (2002). Are the performance overestimates given by boys with ADHD self-protective? Journal of Clinical Child Psychology, 31, 230-241. doi:10.1207/S15374424JCCP3102_08

Ohan, J. L., \& Johnston, C. (2011). Positive illusions of social competence in girls with and without ADHD. Journal of Abnormal Child Psychology, 39, 527-539. doi:10.1007/s10802010-9484-0

O’Neill, M. E., \& Douglas, V. L. (1991). Study strategies and story recall in attention deficit disorder and reading disability. Journal of Abnormal Child Psychology, 19, 671-692. doi:10.1007/BF00918906 
Owens, J. S., Goldfine, M. E., Evangelista, N. M., Hoza, B., \& Kaiser, N. M. (2007). A critical review of self-perceptions and the positive illusory bias in children with ADHD. Clinical Child and Family Psychology Review, 10, 335-351. doi:10.1007/s10567-007-0027-3

Owens, J. S., \& Hoza, B. (2003). The role of inattention and hyperactivity/impulsivity in the positive illusory bias. Journal of Consulting and Clinical Psychology, 71, 680-691. doi:10.1037/0022-006X.71.4.680

Pardini, D. A., Barry, T. D., Barth, J. M., Lochman, J. E., \& Wells, K. C. (2006). Self-perceived social acceptance and peer social standing in children with aggressive-disruptive behaviors. Social Development, 15, 46-64. doi:10.1111/j.1467-9507.2006.00329.x

Sandstrom, M. J., \& Herlan, R. D. (2007). Threatened egotism or confirmed inadequacy? How children's perceptions of social status influence aggressive behavior toward peers. Journal of Social and Clinical Psychology, 26, 240-267. doi:10.1521/jscp.2007.26.2.240

Silk, J. S., Stroud, L. R., Siegle, G. J., Dahl, R. E., Lee, K. H., \& Nelson, E. E. (2012). Peer acceptance and rejection through the eyes of youth: Pupillary, eyetracking and ecological data from the Chatroom Interact task. Social Cognitive and Affective Neuroscience, 7, 93105. doi:10.1093/scan/nsr044

Swanson, E. N., Owens, E. B., \& Hinshaw, S. P. (2012). Is the positive illusory bias illusory? Examining discrepant self-perceptions of competence in girls with ADHD. Journal of Abnormal Child Psychology, 40, 987-998. doi:10.1007/s10802-012-9615-x

Treuting, J. J., \& Hinshaw, S. P. (2001). Depression and self-esteem in boys with attentiondeficit/hyperactivity disorder: Associations with comorbid aggression and explanatory attributional mechanisms. Journal of Abnormal Child Psychology, 29, 23-39. doi:10.1023/A:1005247412221 
Table 1

Descriptive Statistics for Participating Families

\begin{tabular}{|c|c|c|c|c|c|c|}
\hline \multirow[b]{2}{*}{ Variable } & \multicolumn{2}{|c|}{ ADHD Group } & \multicolumn{2}{|c|}{ Non-ADHD Group } & \multirow[b]{2}{*}{$t$} & \multirow[b]{2}{*}{$d f$} \\
\hline & $M(S D)$ & Range & $M(S D)$ & Range & & \\
\hline Child age in years & $10.50(1.34)$ & $8.16-12.83$ & $10.00(1.23)$ & $8.08-12.58$ & -1.76 & 79 \\
\hline Family SES & $41.16(14.04)$ & $20.00-66.00$ & $50.28(12.18)$ & $14.00-66.00$ & $3.13^{*}$ & 79 \\
\hline Number of siblings & $1.24(.78)$ & $.00-4.00$ & $1.15(.84)$ & $.00-3.00$ & -.45 & 78 \\
\hline ADHD-IV RS parent-endorsed & $7.54(1.44)$ & $3.00-9.00$ & $.63(1.02)$ & $0.00-4.00$ & $-24.14 * *$ & 58.38 \\
\hline \multicolumn{7}{|l|}{ inattention symptoms $^{\mathrm{a}}$} \\
\hline ADHD-IV RS parent-endorsed & $5.00(2.47)$ & $1.00-9.00$ & $.65(.87)$ & $0.00-3.00$ & $-9.94 * *$ & 40.50 \\
\hline \multicolumn{7}{|c|}{ hyperactivity/impulsivity symptoms ${ }^{\mathrm{a}}$} \\
\hline ADHD-IV RS teacher-endorsed & $5.29(2.76)$ & $1.00-9.00$ & NA & NA & NA & NA \\
\hline \multicolumn{7}{|l|}{ inattention symptoms ${ }^{\mathrm{a}}$} \\
\hline ADHD-IV RS teacher-endorsed & $3.24(2.61)$ & $0.00-9.00$ & NA & NA & NA & NA \\
\hline
\end{tabular}

Note. ADHD = Attention-Deficit/Hyperactivity Disorder; SES = socioeconomic status score: $8=$ low SES, $66=$ high SES;

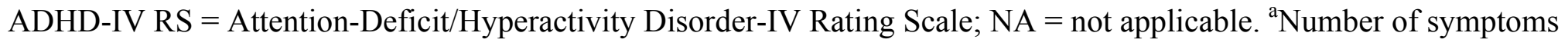
endorsed reflects symptoms rated as 2 or $3(2=$ often, $3=$ very often $){ }^{*} p<.01 .{ }^{* *} p<.001$ 
Table 2

Descriptive Statistics for Ratings of Competence

\begin{tabular}{|c|c|c|c|c|}
\hline \multirow[b]{2}{*}{ Variable } & \multicolumn{2}{|c|}{ ADHD Group } & \multicolumn{2}{|c|}{ Non-ADHD Group } \\
\hline & $M(S D)$ & Range & $M(S D)$ & Range \\
\hline PSP unclear feedback task & $5.72(1.20)$ & $3.50-8.75$ & $5.73(1.12)$ & $3.50-9.00$ \\
\hline PSP positive feedback task & $7.73(.92)$ & $6.00-9.00$ & $7.45(1.00)$ & $4.50-9.00$ \\
\hline PSP negative feedback task & $2.74(1.19)$ & $1.00-5.50$ & $2.99(1.20)$ & $1.00-5.25$ \\
\hline SPPC child report & $2.81(.76)$ & $1.33-4.00$ & $2.92(.53)$ & $1.00-3.83$ \\
\hline PRSCAB parent report & $2.56(.88)$ & $1.00-4.00$ & $3.18(.59)$ & $1.67-4.00$ \\
\hline SPPC unstandardized difference & $.25(1.13)$ & $-2.17-2.17$ & $-.26(.61)$ & $-2.00-.67$ \\
\hline SPPC standardized difference & $.35(1.58)$ & $-3.11-3.08$ & $-.26(.86)$ & $-3.06-1.03$ \\
\hline
\end{tabular}

Note. ADHD = Attention-Deficit/Hyperactivity Disorder; PRSCAB = Parent's Rating Scale of Child's Actual Behavior; PSP =

Post-task Self-evaluations of Performance; SPPC = Self-Perception Profile for Children. 
Table 3

Bivariate Correlations among Dependent Variables

\section{Correlations}

\begin{tabular}{|c|c|c|c|c|}
\hline Variables & 1 & 2 & 3 & 4 \\
\hline 1. PSP unclear feedback task & - & $.36^{*}$ & $.29^{*}$ & .14 \\
\hline 2. PSP positive feedback task & & - & -.09 & .01 \\
\hline 3. PSP negative feedback task & & & - & .21 \\
\hline 4. SPPC standardized difference & & & & - \\
\hline
\end{tabular}

Note. PSP $=$ Post-task Self-evaluations of Performance; SPPC $=$ Self-Perception Profile for Children. ${ }^{*} p<.01$. 


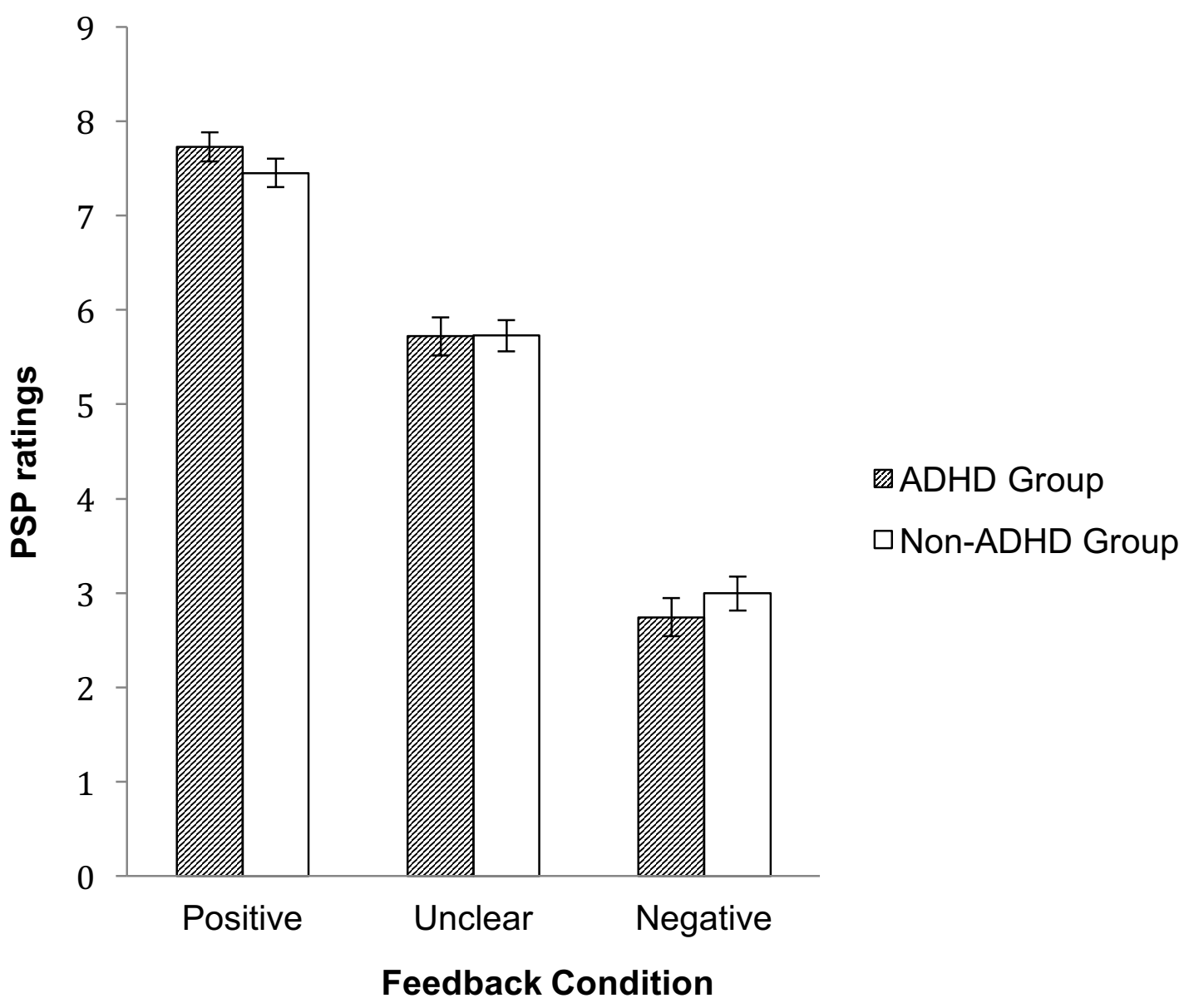

Fig. I Group differences in self-ratings for each feedback condition. ADHD = AttentionDeficit/Hyperactivity Disorder. PSP $=$ Post-task Self-evaluations of Performance. Error bars represent standard errors 